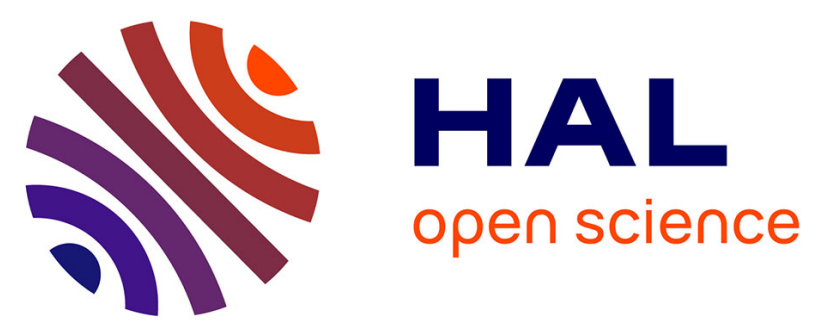

\title{
CTLA-4 +49A $>$ G polymorphism of recipients of HLA-matched sibling allogeneic stem cell transplantation is associated with survival and relapse incidence
}

Patrizia Piccioli, Giuseppe Balbi, Martina Serra, Anna Morabito, Teresa

Lamparelli, Marco Gobbi, Stefania Laurent, Beatrice Dozin, Paolo Bruzzi, Anna Maria Ferraris, et al.

\section{- To cite this version:}

Patrizia Piccioli, Giuseppe Balbi, Martina Serra, Anna Morabito, Teresa Lamparelli, et al.. CTLA$4+49 \mathrm{~A}>\mathrm{G}$ polymorphism of recipients of HLA-matched sibling allogeneic stem cell transplantation is associated with survival and relapse incidence. Annals of Hematology, 2009, 89 (6), pp.613-618. 10.1007/s00277-009-0885-5 . hal-00493086

\section{HAL Id: hal-00493086 https://hal.science/hal-00493086}

Submitted on 18 Jun 2010

HAL is a multi-disciplinary open access archive for the deposit and dissemination of scientific research documents, whether they are published or not. The documents may come from teaching and research institutions in France or abroad, or from public or private research centers.
L'archive ouverte pluridisciplinaire HAL, est destinée au dépôt et à la diffusion de documents scientifiques de niveau recherche, publiés ou non, émanant des établissements d'enseignement et de recherche français ou étrangers, des laboratoires publics ou privés. 


\section{Editorial Manager(tm) for Annals of Hematology}

Manuscript Draft

Manuscript Number: AOHE-D-09-00069R3

Title: CTLA-4 +49A>G polymorphism of recipients of HLA-matched sibling allogeneic stem cell transplantation is associated with survival and relapse incidence

Article Type: Original Article

Keywords: CTLA-4 polymorphism; transplant outcome; survival; disease relapse

Corresponding Author: Dr. Maria Pia Pistillo, Biology

Corresponding Author's Institution: Istituto Nazionale per la Ricerca sul Cancro, Genova

First Author: Patrizia Piccioli, PhD

Order of Authors: Patrizia Piccioli, PhD; Giuseppe Balbi, PhD; Martina Serra; Anna Morabito; Teresa Lamparelli, MD; Marco Gobbi, MD; Stefania Laurent, PhD; Beatrice Dozin, PhD; Paolo Bruzzi, MD; Andrea Bacigalupo, MD; Rosario Notaro, MD; Maria Pia Pistillo, PhD

Abstract: Conflicting observations have been reported about the role of CTLA-4 gene polymorphisms in the clinical outcome of allogenic hematopoietic stem cell transplantation (HSCT). We have investigated 3 polymorphisms of the CTLA-4 gene $(-318 \mathrm{C}>\mathrm{T},+49 \mathrm{~A}>\mathrm{G}, \mathrm{CT} 60 \mathrm{G}>\mathrm{A})$ in 133 donor/recipient pairs who underwent HLA-matched sibling donor HSCT for hematological malignancies. We found no association of the clinical outcome of the HSCT with either recipient or donor $-318 \mathrm{C}>\mathrm{T}$ and $\mathrm{CT} 60 \mathrm{G}>\mathrm{A}$ polymorphisms. At variance, we found a significant association of donor $+49 \mathrm{~A}>\mathrm{G}$ GG genotype with longer overall survival (OS) (log rank $\mathrm{P}=0.04)$, and the number of $+49 \mathrm{~A}>\mathrm{G} \mathrm{G}$-alleles in the recipient with longer OS ( $P$ for trend=0.027), longer disease-free survival ( $P$ for trend $=0.036$ ) and reduced relapse rate ( $P$ for trend $=0.042$ ). However, only recipient $+49 A>G$ polymorphism was retained as independent prognostic factor in a multivariate analysis, suggesting that the expression of CTLA-4 on the cells of recipient may be relevant for the clinical outcome of HSCT.

Response to Reviewers: Jurgen Finke, MD

Associate Editor

Annals of Hematology December 2, 2009

Dear Editor,

I am hereby submitting the third revised version of our manuscript Ref. No: AOHE-D-09-00069 entitled "CTLA-4 +49 A>G polymorphism of recipients of HLA-matched sibling allogeneic stem cell transplantation is associated with survival and relapse incidence".

As suggested, we have now addressed the minor comments of Reviewer \#1 as follows. Modifications are underlined.

\section{REVIEWER \#1}

Point 1 
According to the Reviewer's request, we have indicated in the figure that the $\mathrm{p}$ values are from the log rank test. In the figure legend, we have also specified that the log rank test estimates differences in terms of OS or DFS among the 3 genotypes of Recipient considered as separate discrete categories $(+49 \mathrm{GG}, \mathrm{AG}, \mathrm{AA})$.

As requested we have included "* $\log$ rank $\mathrm{p}=0.027 "$ and $" * \log$ rank $\mathrm{p}=0.036 "$ at the bottom left of the OS and DFS graphics, respectively, in Figure 1 and the following new sentence: "* the P values, obtained by log rank tests, refer to the differences in terms of OS and DFS across the 3 subgroupss of the discrete variable (recipient genotype)" in the Legend to Figure 1.

Point 2

In the last paragraph of Results, page 8, line 1, the word "response" has been deleted with the new sentence becoming: "In view of these results and of the known unfavorable effect of acute GvHD on both OS and DFS, we further investigated a possible correlation between acute, as well as chronic GvHD, and the $+49 \mathrm{~A} / \mathrm{G}$ or $\mathrm{G} / \mathrm{G}$ recipient genotype".

\section{Point 3}

Since this statistical analysis was not performed, we agree with the Reviewer that our sentence was too speculative. We thus have deleted the following sentence: "According to this hypothesis, the GvL effect in our series of patients was independent from the severity of GVHD" in the Discussion Page 10, lines 8-9.

We believe that we have addressed the minor concerns raised by the Reviewer \# 1 and hope that the revised manuscript will meet the requirements for publication in Annals of Hematology.

We thank you very much for your attention and look forward to hearing from you.

Yours sincerely,

Maria Pia Pistillo

Maria Pia Pistillo, PhD

Breast Cancer Laboratory of

Tumor Genetics Unit

National Cancer Research Institute

L.go R. Benzi, 10

16132 Genovaltaly Phone: +390105737538 
CTLA-4 +49A>G polymorphism of recipients of HLA-matched sibling allogeneic stem cell transplantation is associated with survival and relapse incidence.

Patrizia Piccioli ${ }^{1}$, Giuseppe Balbi ${ }^{2}$, Martina Serra ${ }^{1}$, Anna Morabito ${ }^{3}$, Teresa Lamparelli ${ }^{4}$, Marco Gobbi ${ }^{5}$, Stefania Laurent ${ }^{3}$, Beatrice Dozin ${ }^{6}$, Paolo Bruzzi ${ }^{6}$, Anna Maria Ferraris ${ }^{7}$, Andrea Bacigalupo ${ }^{4}$, Rosario Notaro ${ }^{8}$, Maria Pia Pistillo ${ }^{3} *$

*These authors equally contributed to the work.

Brief title: CTLA-4 +49 A>G polymorphism and HSCT outcome

\section{P.Piccioli}

Medical Oncology C,

National Cancer Research Institute,

Genoa, Italy

G. Balbi

Department of Oncology, Biology and Genetics,

University of Genoa,

Genoa, Italy

\section{Serra}

Medical Oncology C,

National Cancer Research Institute,

Genoa, Italy

\section{A. Morabito}

Breast Cancer Laboratory of Tumour Genetics Unit,

National Cancer Research Institute,

Genoa, Italy

T. Lamparelli, Division of Hematology, San Martino Hospital,

Genoa, Italy

\section{Gobbi}

Department of Hematology and Oncology, University of Genoa,

Genoa, Italy

S. Laurent

Breast Cancer Laboratory of Tumour Genetics Unit, 
National Cancer Research Institute,

Genoa, Italy

B. Dozin

Clinical Epidemiology Unit,

National Cancer Research Institute,

Genoa, Italy

P. Bruzzi

Clinical Epidemiology Unit,

National Cancer Research Institute,

Genoa, Italy

Anna Maria Ferraris

University of Genoa and National Cancer Research Institute,

Genoa, Italy

\author{
A. Bacigalupo \\ Division of Hematology, \\ San Martino Hospital, \\ Genoa, Italy \\ R. Notaro \\ Laboratory of Genetics and Gene Transfer, Core Research Laboratory, \\ Istituto Toscano Tumori (CRL-ITT), \\ Florence, Italy \\ M.P. Pistillo \\ Breast Cancer Laboratory of Tumour Genetics Unit, \\ National Cancer Research Institute, \\ Genoa, Italy
}

Correspondence: Maria Pia Pistillo, Breast Cancer Laboratory of Tumour Genetics Unit, National Cancer Research Institute, L.go R. Benzi 10, 16132 Genoa, Italy.

Phone: +390105737588, Fax: +390105737489, e-mail: mariapia.pistillo@istge.it 


\begin{abstract}
Conflicting observations have been reported about the role of CTLA-4 gene polymorphisms in the clinical outcome of allogeneic hematopoietic stem cell transplantation (HSCT). We have investigated 3 polymorphisms of the CTLA-4 gene $(-318 \mathrm{C}>\mathrm{T},+49 \mathrm{~A}>\mathrm{G}, \mathrm{CT} 60 \mathrm{G}>\mathrm{A})$ in 133 donor/recipient pairs who underwent HLA-matched sibling donor HSCT for hematological malignancies. We found no association of the clinical outcome of the HSCT with either recipient or donor $-318 \mathrm{C}>\mathrm{T}$ and $\mathrm{CT} 60 \mathrm{G}>\mathrm{A}$ polymorphisms. At variance, we found a significant association of donor $+49 \mathrm{~A}>\mathrm{G}$ G/G genotype with longer overall survival (OS) (log rank $P=0.04$ ), and the number of $+49 \mathrm{~A}>\mathrm{G}$ G-alleles in the recipient with longer $\mathrm{OS}$ $(P=0.027)$, longer disease-free survival $(P=0.036)$ and reduced relapse rate $(P=0.042)$. However, only recipient $+49 \mathrm{~A}>\mathrm{G}$ polymorphism was retained as independent prognostic factor in a multivariate analysis, suggesting that the expression of CTLA-4 on the cells of recipient may be relevant for the clinical outcome of HSCT.
\end{abstract}

Keywords: CTLA-4 polymorphism; transplant outcome; survival; disease relapse 


\section{Introduction}

Cytotoxic T-lymphocyte antigen-4 (CTLA-4) is a negative regulator of T-cell activation $[1,2]$ which, as suggested by studies in animal models of transplant [3-5], may contribute to modulate immune response and tolerance in both solid organ and hematopoietic stem cell transplantation (HSCT).

Few polymorphisms in the CTLA-4 gene, likely because they may affect the inhibitory function of CTLA-4 [6,7], have been found associated with the susceptibility to autoimmune diseases [6-9] and recently with the outcome of allogeneic hematopoietic stem cell transplantation (HSCT). In a multicentric study, Perez-Garcia et al. have investigated CTLA-4 gene polymorphisms in human leukocyte antigen (HLA)-identical sibling donor HSCT; they found that the presence of at least one G-allele of CT60 polymorphism in the donors was associated with reduced overall survival (OS), higher relapse risk and lower risk of acute graft-versus-host disease (GvHD) [10]. Vannucchi et al., in unrelated HLA-matched donor HSCT, confirmed the association with GvHD but not with OS and relapse [11]. Azarian et al., in HLA-identical sibling donor HSCT, found the association of chronic GvHD only with donor $+49 \mathrm{~A}>\mathrm{G}$ G/G genotype [12].

In this study, we have retrospectively investigated the influence of both donor and recipient CTLA-4 gene polymorphisms $(-318 \mathrm{C}>\mathrm{T},+49 \mathrm{~A}>\mathrm{G}$ and $\mathrm{CT} 60 \mathrm{G}>\mathrm{A})$ on the clinical outcome of HLA-identical sibling donor HSCT. 


\section{Material and Methods}

Patients The study included 133 consecutive donor-recipient pairs in which the recipient underwent HLA-identical sibling donor HSCT for hematological malignancies in a single center (San Martino Hospital, Genoa, Italy) between 1994 and 1999. All patients underwent a long follow-up observation (median 6.5 years, range 13 days-12.2 years). The informed consent was obtained according to institutional procedures and to the declaration of Helsinki. Patient characteristics are summarized in Table 1 . The median age of patients was 40 years (range 17-65) and that of donors was 38 years (range 10-59). Sex mismatch between donor and recipient was present in 71 pairs. All patients have been transplanted with unmanipulated HLA-identical sibling hematopoietic stem cells derived either from peripheral blood $(n=95)$ or from bone marrow $(n=38)$. One hundred and twenty-six patients received a myeloablative conditioning regimen that in 81 patients included the total body irradiation (TBI), and 7 patients received a reduced intensity conditioning regimen. The prophylaxis of GvHD was performed in all patients with cyclosporine and methotrexate (MTX). Twenty-seven patients received donor lymphocyte infusions (DLI).

\section{CTLA-4 genotyping}

Whole peripheral blood samples were collected from donors and from recipients before HSCT and genomic DNA was extracted by standard methods. CTLA-4 -318 C>T (promoter) and $+49 \mathrm{~A}>\mathrm{G}$ (exon 1) polymorphisms have been genotyped by a previously described tetraprimer amplification refractory mutation system (T-ARMS-PCR) [13,14]. CT60 G>A (3' UTR) polymorphism has been genotyped by a newly developed T-ARMS-PCR (details available on request). 


\section{Statistical analysis}

Deviation from Hardy Weinberg equilibrium (HWE) was tested with Pearson's $\chi^{2}$ test using the Finetti program (Authors: Wienker \& Strom; http://ihg.gsf.de/cgi-bin/hw/hwa1.pl). Overall survival (OS) and disease-free survival (DFS) have been analyzed by Kaplan Meier method and compared using the log-rank test. Multivariate Cox regression models (backward stepwise method) have been performed to evaluate the combined effect of the following variables: age and sex of recipient and of donor, sex mismatch, type and stage of disease, source of stem cells, TBI, and donor and recipient $+49 \mathrm{~A}>\mathrm{G}$ genotypes. Since investigated polymorphisms are likely to affect gene expression (or the activity of the gene product), it is expected that the levels of expression in heterozygotes are intermediate in the respect of homozygotes: thus, the association with genotypes have been tested with Mantel-Haenszel chi-square test for trend. Kaplan-Meier analyses and Cox's regressions were performed using the SPSS package (version 13.0 for Windows). All statistical tests were two-sided; statistical significance has been accepted for any $P<0.05$. 


\section{Results}

We have genotyped 3 polymorphisms of $C T L A-4$ gene $(-318 \mathrm{C}>\mathrm{T}$, promoter; $+49 \mathrm{~A}>\mathrm{G}$, exon 1; CT60G >A, 3'UTR) in 133 pairs of donors and recipients who underwent HLA-matched sibling donor HSCT for hematological malignancies in a single center. Genotype frequencies of all 3 polymorphisms (Table 2) fit the Hardy-Weinberg equilibrium in both recipients and donors and were similar to that found in the Italian population $[13,15,16]$ and in the HSCT series reported by Perez-Garcia et al. [10].

We found no correlation between the $+49 \mathrm{~A}>\mathrm{G}$ donor and recipient genotype and either one of acute or chronic GvHD. Similarly, none of the donor and recipient $-318 \mathrm{C}>\mathrm{T}$ or CT60G>A polymorphisms appeared associated with GvHD. Furthemore, transplant outcome (survival or disease relapse) was not associated with $-318 \mathrm{C}>\mathrm{T}$ or $\mathrm{CT} 60 \mathrm{G}>\mathrm{A}$ polymorphisms in either recipient or donor (not shown).In contrast with previous report [10], we have observed a longer OS in patients transplanted from a donor that was homozygote $\mathrm{G} / \mathrm{G}$ for the $+49 \mathrm{~A}>\mathrm{G}$ polymorphism (5-year OS: A/A, 51\%; A/G, 46\%; G/G, 87\%; log rank $P=0.04$ ). The analysis of CTLA-4 polymorphisms in HSCT recipients, analysis that has not been performed in the previous studies $[10,12]$, has shown that the number of $+49 A>G$ G-alleles in the recipient was significantly associated with longer OS (5-year OS: A/A, 46\%; A/G, 55\%; G/G, 90\%; log rank $P=0.027$; figure 1A), longer DFS (5-year DFS: A/A, 59\%; A/G, 68\%; G/G, 80\%; log rank $P=0.036$; figure 1B) and reduced relapse rate (A/A, 43\%; $\mathrm{A} / \mathrm{G}, 28 \% ; \mathrm{G} / \mathrm{G}, 20 \%$; log rank $P=0.042$; data not shown). Interestingly, the total number of $+49 \mathrm{~A}>\mathrm{G}$ G-alleles carried by each donor/recipient pair appeared associated with longer OS (5-year OS: 3 or 4-G-alleles, $87 \%$; $\leq 2$ G-alleles, $49 \%$; log rank $P=0.02$ ); however, this association is mostly due to the sibling relationship between recipients and donors that results in a high proportion of pairs in which recipient and donor have the same genotype $\left(\chi^{2}=75.8 ; \mathrm{P}<10^{-6}\right)$. The relative role of donor and of recipient $+49 \mathrm{~A}>\mathrm{G}$ polymorphism in the clinical outcome of HSCT has been 
further evaluated by a multivariate Cox's regression model including relevant clinical variables (listed in "material and methods") and donor and recipient $+49 \mathrm{~A}>\mathrm{G}$ polymorphism (Table 3). Only disease stage (advanced vs early) and the recipient $+49 \mathrm{~A}>\mathrm{G}$ genotype have been retained in the final model of OS as significant independent predictors of survival; the hazard of death was much higher in patients with advanced disease as compared to those with early disease $(\mathrm{HR}=2.63,95 \% \mathrm{CI} 1.59-4.34, \mathrm{p}<0.001)$; with respect to the wild-type genotype $\mathrm{A} / \mathrm{A}$, the hazard of death was gradually decreasing according to the number of G-alleles in the recipient $(\mathrm{HR}$ for $\mathrm{A} / \mathrm{G}$ genotype $=0.67,95 \% \mathrm{CI} 0.40-1.10 ; \mathrm{HR}$ for $\mathrm{G} / \mathrm{G}$ genotype $=0.09$, 95\%CI 0.13-0.72, $P$ for trend=0.014). Disease stage $(\mathrm{HR}=2.15$ 95\%CI 1.19-3.89, $P<0.011)$ and recipient $+49 \mathrm{~A}>\mathrm{G}$ genotype $(\mathrm{HR}$ for $\mathrm{A} / \mathrm{G}$ genotype $=0.53,95 \% \mathrm{CI} \quad 0.29-0.97 ; \mathrm{HR}$ for $\mathrm{G} / \mathrm{G}$ genotype $=0.26,95 \% \mathrm{CI} 0.06-1.12, P$ for trend $=0.025)$ were also significantly associated with DFS, as well as TBI (HR of absence of TBI treatment vs TBI treatment $=2.84$, 95\% CI 1.55 5.24, $p<0.001)$. Thus the multivariate analysis confirmed the independent prognostic significance of recipient, but not of donor, $+49 \mathrm{~A}>\mathrm{G}$ genotypes for both $\mathrm{OS}$ and DFS.

In view of these results and of the known unfavorable effect of acute GvHD on both OS and DFS, we further investigated a possible correlation between acute, as well as chronic GvHD, and the $+49 \mathrm{~A} / \mathrm{G}$ or $\mathrm{G} / \mathrm{G}$ recipient genotype. When considering these genotypes versus the wild type A/A genotype, we did not find any significant reduced severity of either one of the GvHD types (acute GvHD, OR of grade 0-1 vs 2-4: 1.02, 95\%CI 0.51-2.03, p=0.954; chronic GvHD, OR of limited vs moderate-extenxsive: $1.84,95 \%$ CI $0.86-3.85, \mathrm{p}=0.103$ ). 


\section{Discussion}

We have investigated CTLA-4 gene polymorphisms in a series of 133 HSCT recipients (and their HLA-matched sibling donors) that have been enrolled in a relatively short lapse of time (1994-99) in a single Center and that have a long follow-up (median 6.5 years). In this study, we have not confirmed the previously reported effects of donor $+49 \mathrm{~A}>\mathrm{G}$ and of donor CT60G >A polymorphisms on the clinical outcome of HSCT [10]: in particular we have observed that patients transplanted from a donor carrying at least one G-allele of CT60 polymorphism have, without reaching statistical significance, a longer and not a reduced OS (5-year OS: A/A, 46\%; A/G and G/G, 55\%; $P=0.4$ ). Such discrepancies could be explained, in part, by the different clinical features of patients included in these series of HLA-matched sibling donor HSCT: in fact Perez-Garcia's study [10] included a smaller proportion of (i) gender mismatch ( $25 \%$ vs. $53 \%$; $P<0.001)$, (ii) bone marrow as stem-cells source $(50 \%$ vs. $29 \% ; P<0.001)$ and (iii) total body irradiation (38\% vs. $61 \% ; P=0.001)$.

On the other hand our data, supported by the multivariate analysis, show that recipient CTLA$4+49 \mathrm{~A}>\mathrm{G}$ gene polymorphism, which had not been investigated so far in the setting of HLAmatched sibling donor HSCT $[10,12]$ may be relevant for the clinical outcome of HSCT. This surprising and unexpected finding suggests that $C T L A-4$ might play a role in post-transplant control of disease through its expression on the recipient cells that include leukemic cells $[17,18]$, recipient monocytes [19] and regulatory $\mathrm{T}$ cells of recipient origin that can persist after myeloablative treatments [20]. The $+49 \mathrm{~A}>\mathrm{G}$ G-allele has been associated with the decreased expression of CTLA-4 gene [21] and the overall reduced function of its product [6,7]: this could result in an increased activation of $\mathrm{T}$ cells that explains the reported association of $+49 \mathrm{~A}>\mathrm{G}$ G-allele with the increased susceptibility to autoimmune disorders [69]. This is in keeping with the longer survival and the reduction of relapse rate we have 
observed in allo-HSCT recipients bearing the $+49 \mathrm{~A}>\mathrm{G}$ G-allele. These recipients may express lower levels of CTLA-4 on either leukemic (or micro-environment) cells, and this could result in a reduced interaction of $C T L A-4$ with $\mathrm{B} 7$ molecules expressed on donor T cells. As it has been found that $\mathrm{T}$ cells may express B7 molecules able to transduce inhibitory signals [22], the reduced $C T L A-4: B 7$ interaction might represent a mechanism leading, eventually, to a more effective control of leukemic cells (graft-versus-leukemia, GvL) by the donor T cells.

It is also suggestive that a recipient-derived GVL effect, in the context of an autoimmune disorder, has been observed in a murine model of hematopoietic transplant after the late blockade of CTLA-4 [5]. In addition, in keeping with our finding, it has been recently reported that the blockade of the CTLA4 molecule may be effective in the treatment of malignancy relapse after allo-HSCT [23]. For all these reasons, if confirmed, our data will provide additional information on the risk for allogeneic transplantation outcome.

Although the intriguing biological hints of our findings, the data about CTLA-4 gene polymorphisms and HSCT reported in various studies [10-12 and present report] remain highly conflicting. This suggests caution in evaluating the possible impact of CTLA-4 gene polymorphisms on the clinical outcome of allogeneic HSCT; therefore, they require validation in properly designed prospective clinical trials. 


\section{Acknowledgments}

This work was supported in part by grants from Ministero dell'Istruzione, dell'Università e della Ricerca (MIUR-PRIN 2007, project WEYB3A) and from Regione Liguria. 


\section{References}

1. Walunas TL, Lenschow DJ, Bakker CY, Linsley PS, Freeman GJ, Green JM, Thompson CB, Bluestone JA (1994) CTLA-4 can function as a negative regulator of $\mathrm{T}$ cell activation. Immunity 1:405-413.

2. Lee KM, Chuang E, Griffin M, Khattri R, Hong DK, Zhang W, Straus D, Samelson LE, Thompson CB, Bluestone JA (1998) Molecular basis of T cell inactivation by CTLA-4. Science 282:2263-2266.

3. Sho M, Yamada A, Najafian N, Salama AD, Harada H, Sandner SE, Sanchez-Fueyo A, Zheng XX, Strom TB, Sayegh MH (2002) Physiological mechanisms of regulating alloimmunity: cytokines, CTLA-4, CD25+ cells, and the alloreactive T cell clone size. J Immunol 169:3744-3751.

4. Ito T, Ueno T, Clarkson MR, Yuan X, Jurewicz MM, Yagita H, Azuma M, Sharpe AH, Auchincloss H Jr, Sayegh MH, Najafian N (2005) Analysis of the role of negative T cell costimulatory pathways in CD4 and CD8 T cell-mediated alloimmune responses in vivo. $\mathrm{J}$ Immunol 174:6648-6656.

5. Fevery S, Billiau AD, Sprangers B, Rutgeerts O, Lenaerts C, Goebels J, Landuyt W, Kasran A, Boon L, Sagaert X, De Wolf-Peeters C, Waer M, Vandenberghe P (2007) CTLA-4 blockade in murine bone marrow chimeras induces a host-derived antileukemic effect without graft-versus-host disease. Leukemia 21:1451-1459.

6. Kouki T, Sawai Y, Gardine CA, Fisfalen ME, Alegre ML, DeGroot LJ (2000) CTLA-4 gene polymorphism at position 49 in exon 1 reduces the inhibitory function of CTLA-4 and contributes to the pathogenesis of Graves' disease. J Immunol 165:6606-6611.

7. Mäurer M, Loserth S, Kolb-Mäurer A, Ponath A, Wiese S, Kruse N, Rieckmann P (2002) A polymorphism in the human cytotoxic T-lymphocyte antigen 4 (CTLA4) gene (exon 1 +49) alters T-cell activation. Immunogenetics 54:1-8. 
8. Ueda H, Howson JM, Esposito L, Heward J, Snook H, Chamberlain G, Rainbow DB, Hunter KM, Smith AN, Di Genova G, Herr MH, Dahlman I et al. (2003) Association of the T-cell regulatory gene CTLA4 with susceptibility to autoimmune disease. Nature 423:506-511.

9. Gough SC, Walker LS, Sansom DM (2005) CTLA4 gene polymorphism and autoimmunity. Immunol Rev 204:102-115.

10. Pérez-García A, De la Cámara R, Román-Gómez J, Jiménez-Velasco A, Encuentra M, Nieto JB, de la Rubia J, Urbano-Ispizúa A, Brunet S, Iriondo A, González M, Serrano D, Espigado I, Solano C, Ribera JM, Pujal JM, Hoyos M, Gallardo D (2007) GVHD/Immunotherapy Committee of the Spanish Group of Hematopoietic Stem Cell TransplantationCTLA-4 polymorphisms and clinical outcome after allogeneic stem cell transplantation from HLA-identical sibling donors. Blood 110:461-467.

11. Vannucchi AM, Guidi S, Guglielmelli P, Glinz S, Lombardini L, Busca A, Locatelli F, Dall'Omo AM, Bosi A (2007) Significance of CTLA-4 and CD14 genetic polymorphisms in clinical outcome after allogeneic stem cell transplantation. Bone Marrow Transplant 40:1001-1002.

12. Azarian M, Busson M, Lepage V, Charron D, Toubert A, Loiseau P, de Latour RP, Rocha V, Socié G (2007) Donor CTLA-4 +49 A/G*G/G genotype is associated with chronic GvHD after HLA-identical haematopoietic stem-cell transplantations. Blood $110: 4623-4624$

13. Balbi G, Ferrera F, Rizzi M, Piccioli P, Morabito A, Cardamone L, Ghio M, Palmisano GL, Carrara P, Pedemonte S, Sessarego M, De Angioletti M, Notaro R, Indiveri F, Pistillo MP (2007) Association of $-318 \mathrm{C} / \mathrm{T}$ and +49 A/G CTLA-4 gene polymorphisms with a clinical subset of Italian patients with systemic sclerosis. Clin Exp Immunol 149:40-47. 
14. Piccioli P, Serra M, Pedemonte S, Balbi G, Loiacono F, Lastraioli S, Gargiulo L, Morabito A, Zuccaro D, Del Mastro L, Pistillo MP, Venturini M, De Angioletti M, Notaro R (2008) Hexa-primer amplification refractory mutation system PCR for the single tube simultaneous genotyping of two close polymorphisms. Clin Chem 54:227-229.

15. Svahn J, Capasso M, Lanciotti M, Marrone A, Haupt R, Bacigalupo A, Pongiglione C, Boschetto L, Longoni D, Pillon M, Pistorio A, Di Michele P, et al. (2005) The polymorphisms $-318 \mathrm{C}>\mathrm{T}$ in the promoter and $49 \mathrm{~A}>\mathrm{G}$ in exon 1 of CTLA4 and the risk of aplastic anemia in a Caucasian population. Bone Marrow Transplant 35 Suppl 1:S89-92.

16. Petrone A, Giorgi G, Galgani A, Alemanno I, Corsello SM, Signore A, Di Mario U, Nisticò L, Cascino I, Buzzetti R (2005) CT60 single nucleotide polymorphisms of the cytotoxic T-lymphocyte-associated antigen-4 gene region is associated with Graves' disease in an Italian population. Thyroid. 15:232-8.

17. Pistillo MP, Tazzari PL, Palmisano GL, Pierri I, Bolognesi A, Ferlito F, Capanni P, Polito L, Ratta M, Pileri S, Piccioli M, Basso G, Rissotto L, Conte R, Gobbi M, Stirpe F, Ferrara GB (2003) CTLA-4 is not restricted to the lymphoid cell lineage and can function as a target molecule for apoptosis induction of leukemic cells. Blood 101:202-209.

18. Laurent S, Palmisano GL, Martelli AM, Kato T, Tazzari PL, Pierri I, Clavio M, Dozin B, Balbi G, Megna M, Morabito A, Lamparelli T, Bacigalupo A, Gobbi M, Pistillo MP (2007) CTLA-4 expressed by chemoresistant, as well as untreated, myeloid leukaemia cells can be targeted with ligands to induce apoptosis. Br J Haematol 136:597-608.

19. Wang XB, Giscombe R, Yan Z, Heiden T, Xu D, Lefvert AK (2002) Expression of CTLA-4 by human monocytes. Scand J Immunol 55:53-60.

20. Madrigal A, Shaw BE (2008) Immunogenetic factors in donors and patients that affect the outcome of hematopoietic stem cell transplantation. Blood Cells Mol Dis 40:40-43. 
21. Anjos S, Nguyen A, Ounissi-Benkalha H, Tessier MC, Polychronakos C (2002) A common autoimmunity predisposing signal peptide variant of the cytotoxic T-lymphocyte antigen 4 results in inefficient glycosylation of the susceptibility allele. J Biol Chem 277:46478-46486.

22. Greenwald RJ, Freeman GJ, Sharpe AH (2005) The B7 family revisited. Annu Rev Immunol 23:515-548.

23. Bashey A, Medina B, Corringham S, Pasek M, Carrier E, Vrooman L, Lowy I, Solomon SR, Morris LE, Holland HK, Mason JR, Alyea EP, Soiffer RJ, Ball ED (2009) CTLA4 blockade with ipilimumab to treat relapse of malignancy after allogeneic hematopoietic cell transplantation. Blood 113:1581-1588. 


\section{Legend to Figure 1}

Kaplan-Meier survival curves according to the genotype of the CTLA-4 +49A>G gene polymorphism of the recipient (A/A, A/G and $G / G)$.

A) Overall survival (OS). $n=$ number of patients at risk. OS with $95 \%$ confidence interval (CI) in parentheses. $P=0.027$.

B) Disease free survival (DFS). $n=$ number of patients at risk. DFS, with $95 \%$ CI in parentheses. $P=0.036$.

* the P values, obtained by log rank tests, refer to the differences in terms of OS and DFS across the 3 subgroupss of the discrete variable (recipient genotype). 
TABLE 1. Patient characteristics

\begin{tabular}{ll}
\hline Feature & n (\%) \\
\hline Number of patients & 133 \\
Median age (range), y & $40(17-65)$ \\
Sex (male:female) & $87: 46$ \\
& \\
Diagnosis & \\
$\quad$ Acute lymphoblastic leukaemia, $n(\%)$ & $17(12.8)$ \\
$\quad$ Acute myeloid leukemia, $n(\%)$ & $39(29.3)$ \\
$\quad$ Myelodysplastic syndrome, $n(\%)$ & $11(8.3)$ \\
$\quad$ Chronic myeloid leukemia, $n(\%)$ & $44(33.1)$ \\
$\quad$ Chronic idiopathic myelofibrosis, $n(\%)$ & $3(2.2)$ \\
$\quad$ Lymphoproliferative disorders, $n(\%)$ & $14(10.5)$ \\
$\quad$ Hodgkin disease, $n(\%)$ & $5(3.8)$ \\
& \\
Disease stage (early:advanced) & $80: 53$ \\
Sex mismatch, $n(\%)$ & $71(53.4)$ \\
Source of stem cells & \\
$\quad$ Bone marrow, $n(\%)$ & $38(28.6)$ \\
$\quad$ Peripheral blood, $n(\%)$ & $95(71.4)$ \\
& \\
Conditioning regimens & \\
Myeloablative regimen with TBI, $n(\%)$ & $81(60.9)$ \\
Myeloablative regimen w/o TBI, $n(\%)$ & $45(33.8)$ \\
Reduced intensity conditioning regimen, $n(\%)$ & $7(5.3)$ \\
& \\
Acute GvHD $\geq$ grade II, $n(\%)$ & $58(43.6)$ \\
Chronic GvHD $\geq$ grade II, $n(\%)$ & $52(39.1)$ \\
Donor lymphocyte infusion, $n(\%)$ & $27(20.3)$ \\
\hline Abbreviations: GvHD: graft- &
\end{tabular}

Abbreviations: GvHD: graft-versus-host disease 
TABLE 2. Genotype and allele frequencies of CTLA-4 polymorphisms in recipients and donors of HLA-identical sibling HSCT

\begin{tabular}{|c|c|c|c|c|c|}
\hline \multirow[t]{2}{*}{ Genotypes } & \multicolumn{2}{|c|}{$n(\%)$} & \multirow[t]{2}{*}{ Alleles } & \multicolumn{2}{|c|}{$n$ (frequency) } \\
\hline & Recipients & Donors & & Recipients & Donors \\
\hline$-318 \mathrm{C}>\mathrm{T}$ & $(n=133)$ & $(n=133)$ & $-318 C>T$ & $(2 n=266)$ & $(2 n=266)$ \\
\hline $\mathrm{C} / \mathrm{C}$ & $106(79.7)$ & $111(83.5)$ & $\mathrm{C}$ & $237(0.89)$ & $242(0.91)$ \\
\hline $\mathrm{C} / \mathrm{T}$ & $25(18.8)$ & $20(15.0)$ & $\mathrm{T}$ & $29(0.11)$ & $24(0.09)$ \\
\hline $\mathrm{T} / \mathrm{T}$ & $2(1.50)$ & $2(1.5)$ & & & \\
\hline$+49 A>G$ & $(n=133)$ & $(n=133)$ & $+49 A>G$ & $(2 n=266)$ & $(2 n=266)$ \\
\hline $\mathrm{A} / \mathrm{A}$ & $65(48.9)$ & $62(46.6)$ & A & $188(0.71)$ & $180(0.68)$ \\
\hline $\mathrm{A} / \mathrm{G}$ & $58(43.6)$ & $56(42.1)$ & $\mathrm{G}$ & $78(0.29)$ & $86(0.32)$ \\
\hline $\mathrm{G} / \mathrm{G}$ & $10(7.5)$ & $15(11.3)$ & & & \\
\hline CT60 G>A & $(n=133)$ & $(n=133)$ & CT60 G>A & $(2 n=266)$ & $(2 n=266)$ \\
\hline $\mathrm{G} / \mathrm{G}$ & $35(26.3)$ & $32(24.1)$ & $\mathrm{G}$ & $125(0.47)$ & $128(0.48)$ \\
\hline $\mathrm{A} / \mathrm{G}$ & $55(41.4)$ & $64(48.1)$ & A & $141(0.53)$ & $138(0.52)$ \\
\hline $\mathrm{A} / \mathrm{A}$ & $43(32.3)$ & $37(27.8)$ & & & \\
\hline
\end{tabular}

Abbreviation: HSCT, hematopoietic stem cell transplantation. 
Figure 1

\section{A. Overall Survival}

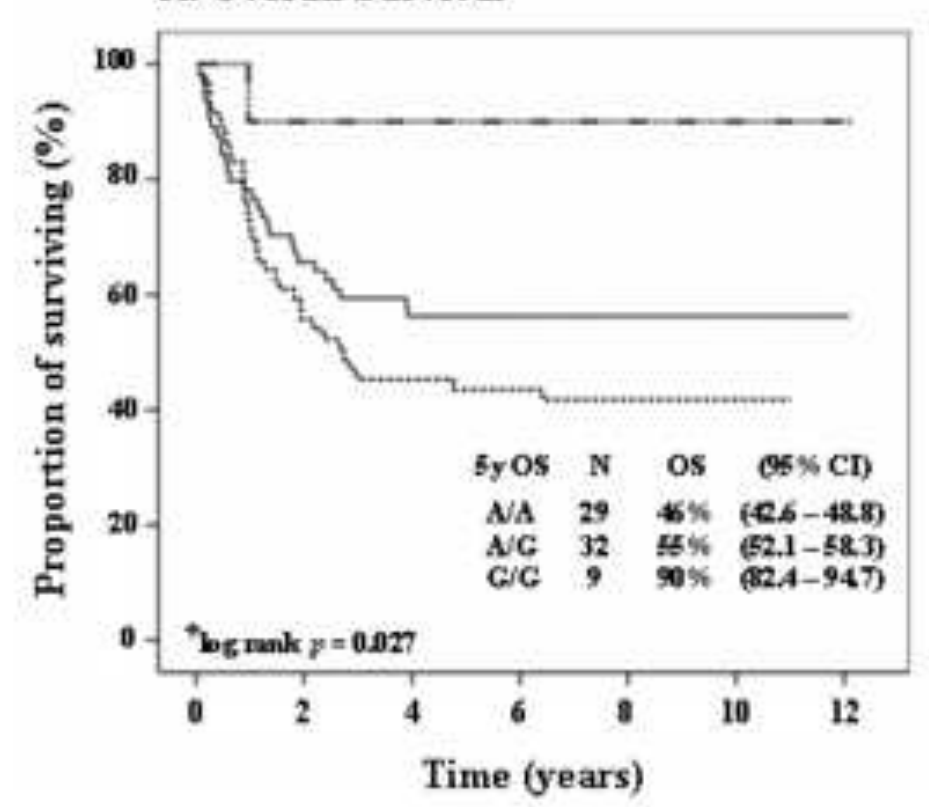

$N^{5}$ patients at risk

$\begin{array}{llllllll}A / A & 65 & 37 & 30 & 29 & 17 & 7 & 0 \\ A / G & 58 & 37 & 32 & 32 & 27 & 13 & 1 \\ \text { G/G } & 10 & 9 & 9 & 9 & 8 & 5 & 1\end{array}$

\section{B. Disease-free Survival}

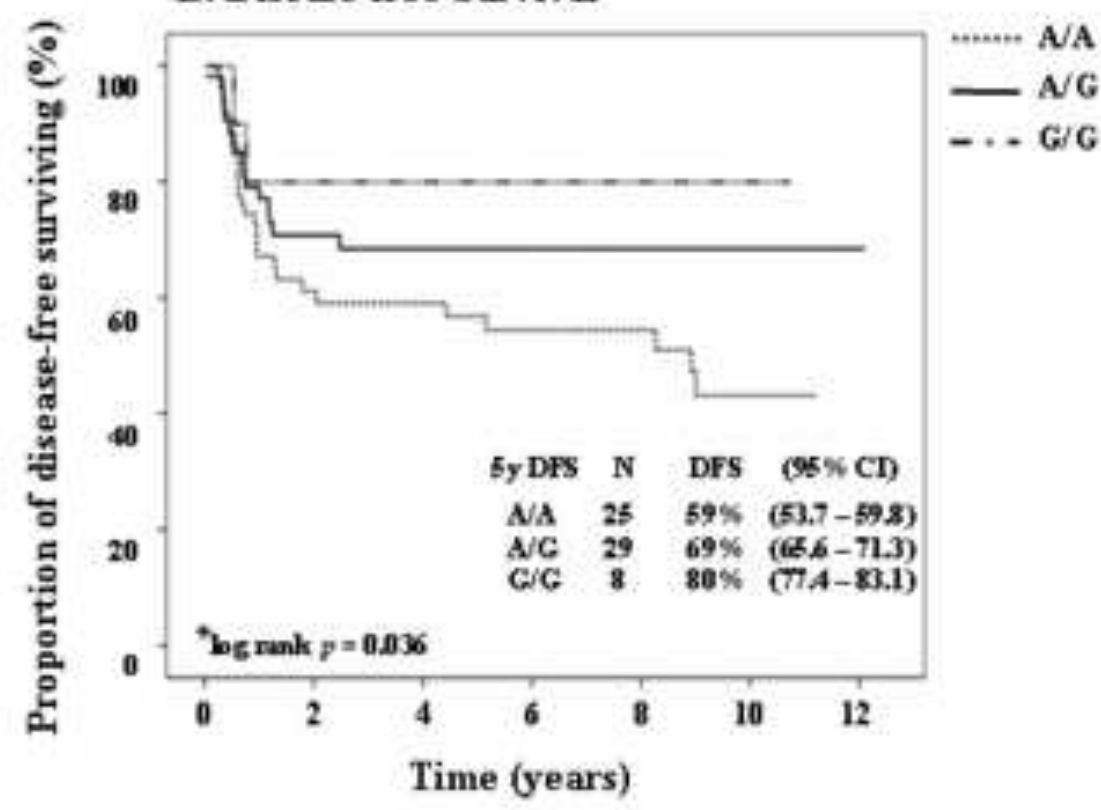

\section{Nopatients at risk}

$\begin{array}{lrrrrrrr}\text { AA } & 65 & 29 & 26 & 23 & 16 & 4 & 0 \\ \text { AG } & 58 & 30 & 29 & 29 & 25 & 13 & 1 \\ \text { GG } & 10 & 7 & 7 & 7 & 7 & 4 & 0\end{array}$


TABLE 3. Multivariate analysis : survivals according to prognostic factors.

Overall Survival

Disease-free Survival

\begin{tabular}{llc}
\hline Factor & $\mathrm{HR}^{\mathrm{II}}$ & $95 \% \mathrm{CI}^{\#}$ \\
\hline $\begin{array}{l}\text { Recipient age } \\
\quad \leq 25\end{array}$ & 1 (ref) & - \\
$26-35 \mathrm{y}$ & 0.92 & $0.35-2.44$ \\
$36-45 \mathrm{y}$ & 1.12 & $0.37-3.36$ \\
$>45 \mathrm{y}$ & 0.89 & $0.25-3.15$
\end{tabular}

$\begin{array}{llc}\begin{array}{c}\text { Donor age } \\ \leq 30 \mathrm{y}\end{array} & 1 \text { (ref) } & - \\ 31-40 \mathrm{y} & 1.49 & 0.72-3.09 \\ 41-49 \mathrm{y} & 1.20 & 0.56-2.59 \\ >49 \mathrm{y} & 1.53 & 0.69-3.37\end{array}$

$\begin{array}{ccc}p \text { value }^{*} & \mathrm{HR}^{\mathrm{II}} & 95 \% \mathrm{CI}^{\sharp} \\ 0.734^{\S *} & & \\ & 1 \text { (ref) } & - \\ & 0.45 & 0.18-1.16 \\ & 0.48 & 0.20-1.17 \\ & 0.70 & 0.31-1.57 \\ 0.419^{\S *} & & \\ & 1 \text { (ref) } & - \\ & 2.08 & 0.66-6.54 \\ & 2.86 & 0.72-3.42 \\ & 3.09 & 0.62-5.29\end{array}$

Recipient gender

male

1 (ref)

$0.996^{\S}$

1 (ref)

$1.56 \quad 0.86-2.82$

Donor gender

$0.85 \quad 0.26-2.73$

$0.971^{\S}$

1 (ref)

$0.290^{\S}$

male

1 (ref)

0.72

$0.219^{\S *}$

female

$0.98 \quad 0.35-2.75$

$0.942^{\S}$

1 (ref)

$0.64 \quad 0.29-1.42$

rec. $\mathrm{M}$ vs don. $\mathrm{M}$

1 (ref)

$0.83 \quad 0.42-1.67$

1.39

0.61-3.16

rec. $\mathrm{F} v s$ don. $\mathrm{M}$

1.02

$0.47-2.25$

rec. F vs don. $\mathrm{F}$

$1.0 \quad 0.42-2.42$

1.08

$0.144^{\S}$

$0.144^{\S *}$

+49A>G recipient genotype $\quad 0.014^{*}$

$\begin{array}{llc}\text { A/A } & 1(\text { ref }) & - \\ \text { A/G } & 0.67 & 0.40-1.10 \\ \text { G/G } & 0.09 & 0.13-0.72\end{array}$

1 (ref)
0.53

$0.43-2.74$

(

$0.26 \quad 0.06-1.12$

$\begin{array}{ccc}+49 A>G \text { donor genotype } & \\ \mathrm{A} / \mathrm{A} & 1 \text { (ref) } & - \\ \mathrm{A} / \mathrm{G} & 1.28 & 0.75-2.19 \\ \mathrm{G} / \mathrm{G} & 0.36 & 0.08-1.69\end{array}$

$0.130^{\S *}$

1 (ref)

$1.12 \quad 0.52-2.40$

$0.81 \quad 0.17-3.98$

Source of stem cells

peripheral blood

bone marrow

1 (ref)

$0.76 \quad 0.45-1.35$

$0.324^{\S}$

$0.492^{\S}$

1 (ref)

$1.28 \quad 0.63-2.61$

Disease type

acute lymphoid

1 (ref)

acute myeloid

0.48

0.73

$0.19-1.17$

lymphoma

0.48

0.30-1.82

myeloproliferative

$0.19-1.23$

$0.369^{\S}$

1 (ref)

$0.309^{\S}$

Disease stage

early

1 (ref)

2.63

$1.59-4.34$

$\begin{array}{ll}0.39 & 0.14-1.05 \\ 0.51 & 0.17-1.48 \\ 0.44 & 0.15-1.28\end{array}$

$0.341^{\S}$

$0.025^{*}$

$0.610^{\S *}$

advanced

$2.63-1.59-4.34$

$<0.001$

1 (ref)

$2.15 \quad 1.19-3.89$

0.011 
1 (ref)

$2.84 \quad 1.55-5.24$

In multivariate Cox regression analyses, all variables were initially included in the model. Variables not significantly associated with overall survival or disease-free survival $(p>0.05)$ were removed from the model by means of a step-down procedure.

"I $\mathrm{HR}$, hazard ratio

\# $95 \%$ CI, $95 \%$ confidence interval

$* p$ value from likehood ratio test

${ }^{*} P$ value from a $\chi^{2}$ test with 1 degree of freedom, assessing the increasing/decreasing trend of HR over the discrete levels of the covariate

$\S$ variable removed from the final model 
Jurgen Finke, MD

Associate Editor

Annals of Hematology

December 2, 2009

Dear Editor,

I am hereby submitting the third revised version of our manuscript Ref. No: AOHE-D-09-00069 entitled "CTLA-4 +49 A>G polymorphism of recipients of HLA-matched sibling allogeneic stem cell transplantation is associated with survival and relapse incidence".

As suggested, we have now addressed the minor comments of Reviewer \#1 as follows. Modifications are underlined.

\section{REVIEWER \#1}

\section{Point 1}

According to the Reviewer's request, we have indicated in the figure that the $\mathrm{p}$ values are from the $\log$ rank test. In the figure legend, we have also specified that the log rank test estimates differences in terms of OS or DFS among the 3 genotypes of Recipient considered as separate discrete categories (+49GG, AG, AA).

As requested we have included "* $\log$ rank $p=0.027$ " and "* $\log$ rank $p=0.036$ " at the bottom left of the OS and DFS graphics, respectively, in Figure 1 and the following new sentence: "** the P values, obtained by log rank tests, refer to the differences in terms of OS and DFS across the 3 subgroupss of the discrete variable (recipient genotype)" in the Legend to Figure 1.

\section{Point 2}

In the last paragraph of Results, page 8, line 1, the word "response" has been deleted with the new sentence becoming: "In view of these results and of the known unfavorable effect of acute GvHD on both OS and DFS, we further investigated a possible correlation between acute, as well as chronic GvHD, and the $+49 \mathrm{~A} / \mathrm{G}$ or G/G recipient genotype".

\section{Point 3}

Since this statistical analysis was not performed, we agree with the Reviewer that our sentence was too speculative. We thus have deleted the following sentence: "According to this hypothesis, the GvL effect in our series of patients was independent from the severity of GVHD" in the Discussion Page 10, lines 8-9.

We believe that we have addressed the minor concerns raised by the Reviewer \#1 and hope that the revised manuscript will meet the requirements for publication in Annals of Hematology.

We thank you very much for your attention and look forward to hearing from you.

Yours sincerely, 
Maria Pia Pistillo

Maria Pia Pistillo, $\mathrm{PhD}$

Breast Cancer Laboratory of

Tumor Genetics Unit

National Cancer Research Institute

L.go R. Benzi, 10

16132 GenovaItaly Phone: +390105737538 